RESEARCH ARTICLE

\title{
Influencer Marketing in the Digital age: The Response to Authentic Creator Content
}

Isaiah Jesse P. Ong, David John V. Teñoso, Miguel Nicholas G. Valmonte, Antonio E. Etrata, Jr., Ph.D.

College of Commerce and Business Administration, University of Santo Tomas, Manila, Philippines

\begin{abstract}
The study aims to determine just how effective influencer marketing is in the digital age, where authenticity and intention can be conflicting factors. With the rapid development in the digital marketing age, the market cannot afford to miss out on a single piece of information considering that it is data that determines the trajectory of businesses. A total of 423 respondents have answered the survey and the data gathered were analyzed using ANOVA and regression. The findings asserted the following: (1) Among the four metrics included in this study, companies tend to choose an influencer/KOL with a good reputation and high credibility over the other influencer metrics, (2) Target customers buy, use, and recommend products of Key Opinion Leaders (KOLs) who have good reputation and high credibility over the other influencer metrics, (3) Target customers buy, accept and recommend products endorsed by influencers over celebrities, (4) Among the influencer/KOL metrics, the target customers prefer reputation and credibility over other metrics, (5) reputation and credibility are significantly associated with influencer marketing, and (6) advertising disclosure, reputation and credibility, and transparency as Key Opinion Leader (KOL) metrics have all positive effect to influencer marketing.
\end{abstract}

Keywords: authentic creator content, digital age, influencer, influencer marketing

\section{Introduction}

From obscure to paramount, the internet has changed the world since its invention in 1991, one industry landscape at a time. In the mid-20th century, the world has officially entered the Digital Age where unlimited information was stored in a search bar, usage of social media platforms took up hours of a day, and, arguably most notably, businesses shifted to digital practices, with some even completely becoming a digital entity.

It has been an age of technological advancement defined by continuous growth and expansion, and through its ever-changing nature, the world is introduced to trends that have inevitably become the key point of strategy. Before the digital shift, businesses from across all industries have utilized traditional offline marketing, such as print, broadcast, direct mail, and phone. While it worked for its time, it did not hold the same reach capacity as what is now called digital marketing strategies. Of the many digital marketing strategies introduced -- marketing features within social media platforms, Google Ads, and the like -- perhaps one of the most prominent ones to 
commence in the Philippine marketing landscape was Influencer Marketing. According to Freberg (2011), a social media professor and author at the University of Louisville, social media influencers (SMIs) are the types of endorsers who can bring considerable amount of influence to audience attitudes through social media. Attributes that make spokespersons influential have been established by mature public relations literature, but little is understood about consumer views of the SMI.

According to Dada (2017), a Forbes Council member, influencers are known to help the brands garner more sales and recognition. Influencers do not necessarily need to have a huge following, as an important factor of being an Influencer is to deliver a clear message to the audience. Other than that, as celebrities are very useful to gain awareness and familiarity, they are mostly classified as celebrity endorsements because they are known to be paid to promote the product, therefore feel more drawn to sales language, but when seeing influencer marketing, the audience are able to trust and connect with the influencer's attitude towards the product/service as it is testimonial (Schouten et al., 2019).

Influencer marketing is also often mistaken as social media advertising, when the two are both very different. According to IZEA (2020), in influencer marketing, trust is an essential key, and around $63 \%$ percent of consumers say that they trust the influencers they follow. Influencers were able to build this trust through connecting and creating a relationship with their followers/ audience. Apart from that, influencer marketing is focused on certain markets, and Influencers have their niches that are to be matched with brands. Personal experiences and authentic content based on their personality are what influencers do in order to accumulate an audience and discreetly urge consumers to buy products from brands. When it comes to social media advertising, the ads come in different forms where costs are flexible, and data are easily tracked. The downside is that consumers often tend to ignore ads, the competition of other ads is vast and innovation with adapting to the new trends is a must to capture attention. These advertisements are usually using sales pitches and languages and are not concentrated on creating consumer relationships.

The purpose of this study focuses on furthering the understanding specifically how different marketing strategies and different personalities of influencers affect the response of the consumers towards the influencers themselves since there are few studies done locally. This aims to further understand how influencer credibility, influencer transparency and advertising disclosure affect influencer marketing itself and how it affects the purchasing behavior of consumers.

\section{Literature Review}

\subsection{Advertising Disclosure}

Brands around the world are very much aware as to how consumers view social media activities and are continuously maximizing the use of major social networking sites such as Facebook, Twitter, and Instagram for increasing profits. Therefore, influencer marketing has become an indispensable tool in the market especially in terms of communication as it provides a special form of engagement with their target audience as well as potential customers at a low price within a short period as compared to their expenses in traditional advertising.

Advertisements that have not been disclosed on social networking sites can be seen as a misleading practice because it is a breach of consumer protection legislation (Weismueller et al., 
2020). This raises the issue of why companies and influencers, particularly those active in influencer marketing, do not always adhere to consumer protection agency requirements Ad disclosures can impact influencer credibility and the intent of the consumer in purchasing and this is acknowledged by social media influencers and the brands (Wodjnski \& Evans, 2015). Traditionally, advertising is known for utilizing the reach of celebrities to the masses and how this impacts consumer consumption. Writers, television personalities, movie stars, and sports figures are among the celebrities who have gained their power and influenced people through traditional media such as radio, and television, etc. Lee (2018) describes non-traditional celebrities such as famous vloggers and bloggers who have gained and reached a certain level of fame through social media sites. This suggests that the influencers that endorse products and brands are used at a micro level showing the organizations' purpose of spending less money on endorsers who are very useful for targeting specific audiences in the market instead of spending more on celebrities with larger appeal to the audience.

Relevant data that informs customers that a promotional message is advertising is referred to as advertising disclosure. There are two distinct sorts of disclosures. Influencers can add a label to their post that says "Paid collaboration with (company name)" to reveal that they are endorsing a product. Alternatively, influencers can use a disclosure hashtag with hashtags like the 'brand name' or 'commercial' to completely declare the product they are endorsing for the viewers to see (Stewart, 2017). The type of disclosure selected for their advertisement may bring a different impact on the credibility of the source along with its purchase intention. This is because the persuasion knowledge model suggests that interpretation among consumers could be relative. Different disclosure types have been examined by previous researches and have concluded that there are different effects on advertising recognition (Wojdynski \& Evans, 2015) and that brand name increases advertising recognition.

Han et al., (2020) conducted research on how straight to the point advertising disclosure affects the consumers' inference specifically on influencers' profound recommendation intent. Their findings revealed that consumers find it less favorable to buy when influencers utilize blatant form advertising disclosures, compared to indirect ones. Thus, it is posited that:

\section{Hol: Advertising disclosure has no direct relationship with influencer marketing}

\subsection{Influencer's Credibility}

Credibility is one of the most important factors in terms of endorsements by celebrities as confirmed by previous research. The source credibility model is a huge help in elaborating the message's efficacy. It proposes the three most powerful source impacts on purchase intention, brand attitudes and advertisement attitudes (Wang \& Scheinbaum, 2017; Phua et al., 2018). In the last few years, the impact of beauty, trustworthiness, and knowledge has been the subject of much debate in social media environments. According to (Shareef et al., 2019), social media advertising value is influenced by credibility, and it is perceived as more credible than conventional media.

Apart from the immediate impression inferred for credibility, researchers note that a statement of disclosure of a hashtag disclosure can have different effects on a consumer's perception of the influencer and their subsequent purchasing behavior. A statement of disclosure reveals that the endorser or the social media influencer has a compensated agreement with a company, implying that 
they are in high demand. Disclosure is an important part of assessing the credibility and transparency of a social media influencer. Lack of information or missing information implies a lack of transparency as well as an ineffective partnership between an influencer and a brand, according to Evans et al. (2017), who argues that missing information leads to poor brand endorsements.

A study has shown that when an Influencer have high levels of extroversion matching with her audiences, her audiences perceive her as more credible. Argyris et al. (2020) focused on the impact of the visual presentation of an influencer's extroversion on perceived credibility and intent to purchase. In contrast, when both the audience and influencer's degree of extroversion are alike, the audience perception towards the credibility of the influencer also decreases. These findings imply that when the target audience considers the personality of the influencer as being comparable from their own, particularly in terms of social desirability and extroversion, the personality of the influencer is perceived as being similar to their own. As a result, it becomes more successful in terms of increasing persuasive results. The compatibility of a personality attribute that is not socially acceptable (poor extroversion, for example) reduces the efficiency of Influencer marketing.

Casais et al. (2021) have conducted a study on how celebrities and influencers' endorsements effect the engagement of the consumers towards the brand in Instagram. A recent study has shown that the Instagram users' engagements rely and depend on the type of influencer they choose to see or follow. This study showed that the posts of the celebrities attracted more followers for the brand, in contrast the influencer's post and publication of the brand has gained more views and visits to the Instagram page of the brand. Overall, the research has shown that the influencers online can affect the consumers perception of the brands. However, the result is that it leads to interaction, but the degree of engagement varies from different types of influencers. Therefore, it is hypothesized that:

\section{Ho2: Influencer's credibility has no direct relationship with influencer marketing}

\subsection{Influencer's Transparency}

When consumers find out that an influencer's branded promotional posts are due to a paid partnership or the financial influence of the brand being advertised, they see the influencer as less transparent when being more ambiguous rather than being very specific on their intentions. The influencer's transparency perceptions have a huge impact on the consumers' perceptions of product efficacy and purchase intentions. (Woodroof et al., 2020). In contrast, (Han et al., 2020) found that when influencers are clear and direct to the point in their disclosure, consumers become less inclined to avail their products compared to subtle advertising disclosures.

Woodroof et al. (2020) has recently conducted a study regarding how the transparency of the influencer affects the efficacy of the products and purchase intentions of the consumers as well. With the sole purpose of examining the influence of the type of advertising disclosure used by the social media influencers on the consumers specifically the transparency of the influencer, the expectations from the performance of the product and how those factors are likely to influence the consumers to purchase the products being advertised, The results have indicated that when consumers become aware or gain knowledge that an influencer's branded promotional post is because of a paid partnership or under the influence of money by the brand being advertised. 
Bentley et al. (2021) conducted a recent study on how to further understand the relationship between the followers and the social media influencers they follow specifically their study focused on understanding the effect of the level of closeness of the social media influencers to their followers. Results have shown that attractiveness and likeability are positive predictors of attitude to the part of the influencer. Closeness serves as a moderator but not without different effects. Closeness has shown positive moderation when it comes to the effect of purchase intentions in terms of attractiveness. However, there is a negative effect when there is an observed similarity on purchase intentions. Overall, closeness served as a moderator in terms of the effect of likeability on attitude on the influencer. It is thus assumed that:

Ho3: Influencer's transparency has no direct relationship with influencer marketing.

\section{Methods}

This study utilized quantitative research design. Quantitative data of the study includes the profile of the respondents, the influencer metrics (including influencer tiers) that should be taken into consideration when identifying the Key Opinion Leaders (hereafter referred to as KOL's) that is featured in a brand's campaign, and the types of market behavior that are anticipated when building and executing an influencer-focused campaign. The respondents of the study are 423 individuals from the National Capital Region of the Philippines aged 18 - 45 who are frequent online shoppers and who are fond of watching influencers on various social media platforms. This study utilized a self-made questionnaire which consists of four parts. A four-point Likert scale was utilized in order to elicit responses on consumers' economic behavior and degree of importance of characteristics KOLs must possess. Descriptive statistics was used to analyze the data gathered in the study. Specifically, frequency count and percent will be used to describe the profile of the respondents. On the other hand, mean and standard deviation were utilized to determine the target respondents' level of agreement on the influencer metrics. multiple regression analysis was utilized to test the significant relationship of the respondents' level of agreement on the influencer metrics and influencer marketing. All the hypotheses in the study were tested at 0.05 level of significance.

\section{Results and Discussions}

\subsection{Table 1}

\section{Multiple Regression Analysis on the Relationship of Influencer Metrics and Influencer Marketing}

\begin{tabular}{|c|c|c|c|c|c|c|}
\hline \multirow{3}{*}{\multicolumn{2}{|c|}{ Model }} & \multirow{2}{*}{\multicolumn{2}{|c|}{$\begin{array}{l}\text { Unstandardized } \\
\text { Coefficients }\end{array}$}} & \multirow{3}{*}{$\begin{array}{l}\text { Standardized } \\
\text { Coefficients } \\
\text { Beta }\end{array}$} & \multirow[t]{3}{*}{$\mathrm{t}$} & \multirow[t]{3}{*}{ Sig. } \\
\hline & & & & & & \\
\hline & & B & \multirow{2}{*}{\begin{tabular}{|l} 
Std. Error \\
25
\end{tabular}} & & & \\
\hline \multirow{4}{*}{1} & (Constant) & 1.28 & & & 5.09 & 00 \\
\hline & Reputation and Credibility & .38 & .06 & .31 & $5.61 *$ & .00 \\
\hline & Advertising Disclosure & .05 & .07 & .04 & $.82^{\mathrm{ns}}$ & .41 \\
\hline & Transparency & .08 & .05 & .08 & $1.46^{\mathrm{ns}}$ & .14 \\
\hline
\end{tabular}

Dependent Variable: Influencer Marketing

*Significant at 0.01

ns - Not Significant 
The main objective of this study is to determine if there is a significant relationship between the respondents' level of agreement on the influencer metrics (including influencer tiers) that should be taken into consideration when identifying the Key Opinion Leaders (hereafter referred to as KOLs) that will be featured in a brand's campaign and the types of market behavior that are anticipated when building and executing an influencer-focused campaign.

Table 1 presents the results involving the relationship of influencer metrics and influencer marketing using multiple regression analysis. As can be gleaned from the table, three metrics were tested if it has a linear relationship with influencer marketing: advertising disclosure, transparency, and reputation and credibility. The table presents the models, unstandardized and standardized coefficients, t-value, and the probability value. Also, it is hypothesized that the three predictors will be positively associated with influencer marketing.

Based on the results, among the three predictors, only reputation and credibility as an influencer metric has a significant linear relationship with influencer marketing. This is supported by a computed t-value of 5.611 along with a probability value of 0.00 . Since the probability value is less than 0.05 , the null hypothesis is rejected. This means that there is a significant linear relationship between reputation and credibility and influencer marketing. Additionally, the table presents the unstandardized and standardized beta weight of reputation and credibility. As evident from the table, reputation and credibility yielded the highest unstandardized beta weight of 0.33 along with a standard error of 0.06 and highest standardized beta weight of 0.31 . This means that reputation and credibility contribute most to effective influencer marketing. Furthermore, since the computed beta (0.38) is positive, this signifies that there is a positive relationship between reputation and credibility and influencer marketing. This means that every one unit increase in the reputation and credibility of an influencer, there is a 0.38 unit increase of influencer marketing.

The findings of this study confirm the results and findings of Argyris et al. (2020) who concentrated on the effects of the visual presentation of an influencer's extroversion on perceived credibility and purchase intentions as mediated by personality matching with the audience. Their study demonstrated that when both the Influencer and her audience have matching levels of high extroversion, the extent to which her audience perceives her as credible increases. In contrast, where both the Influencer and audience possess a similar degree of extroversion, the audience perception towards the credibility of the influencer also decreases. These results suggest that when the target audience is able to perceive Influencer's personality in line with their personality particularly in terms of a social desirability and extroversion. This becomes effective for increasing persuasive outcomes. However, the compatibility of a personality trait that is not considered socially desirable (i.e., low extroversion) decreases the effectiveness of influencer marketing. Casais et al. (2021) conducted a study on the effect of macro celebrity and micro influencer endorsements on consumerbrand engagement in Instagram. The findings of this study have shown that the macro and micro influencers' posts garnered more Instagram users with engagement with jewelry brands. The results have shown that the Instagram users' involvement and interactions depends on the type of influencer of their choice. This study showed that the celebrity's post attracted more followers, in contrast the micro influencer's publication has led to more visits to the brand's Instagram page. Overall, the 
research has shown that online influencers can affect the consumers with brands. However, different types of influencers may result in interactions but with different degree types of engagement.

The second influencer metric investigated if there is a significant relationship with influencer marketing is the influencer's advertising disclosure. As provided, a t-value of 0.82 along with a probability value of 0.41 was computed. Since the probability value is greater than 0.05 , the null hypothesis is not rejected. This means that there is no significant linear relationship between advertising disclosure and influencer marketing. Additionally, the table presents the unstandardized and standardized beta weight of advertising disclosure. As evident from the table, advertising disclosure yielded the lowest unstandardized beta weight of 0.058 along with a standard error of 0.07 and lowest standardized beta weight of .043. This means that reputation and credibility contribute least to effective influencer marketing. Moreover, since the computed beta $(0.058)$ is positive, this signifies that there is a positive relationship between advertising disclosure and influencer marketing. This means that every one unit increase in the advertising disclosure of an influencer, there is a 0.058 unit increase of influencer marketing.

The findings of this research are in contrast with Han et al., (2020). They conducted research on how straight to the point advertising disclosure affects the consumers' inference specifically on influencers' profound recommendation intent. Their findings revealed that consumers find it less favorable to buy when influencers utilize blatant form advertising disclosures, compared to indirect ones.

The third influencer metric tested is the influencer transparency. As the data provides, there is no significant linear relationship between transparency and influencer marketing. This is being supported by a computed t-value of 1.46 along with a probability value of 0.14 . Since the probability value is higher than 0.05 , the null hypothesis is not rejected. Moreover, the table presents the unstandardized and standardized beta weight of reputation and credibility. As evident from the table, transparency yielded an unstandardized beta weight of 0.08 along with a standard error of 0.059 and standardized beta weight of 0.080 . Additionally, since the computed beta $(0.086)$ is positive, this signifies that there is a positive relationship between influencer transparency and influencer marketing. This means that every one unit increase in the transparency of an influencer, there is a 0.08 unit increase of influencer marketing.

The results and findings of this research is in contrast of the findings of Woodroof et al. (2021) who stated that when consumers find out that an influencer's branded promotional posts are due to a paid partnership or the financial influence of the brand being advertised, they see the influencer as less transparent when being more ambiguous rather than being very specific on their intentions. The influencer's transparency perceptions have a huge impact on the consumers' perceptions of product efficacy and purchase intentions. However, this research confirms the findings of Han et al. (2020) who found that when influencers are explicit in their disclosure, consumers become less inclined to avail their products compared to subtle advertising disclosures.

Overall, only transparency as an influencer metric was found to be statistically significant with influencer marketing. However, all the 3 influencer metrics has a positive effect on influencer marketing as evident by the three computed positive beta values. Specifically, reputation and credibility $(\mathrm{B}=0.38, \mathrm{t}=5.61, \mathrm{p}=0.00)$ is positively associated with influencer marketing. 
Conversely, advertising disclosure $(B=0.05, t=0.82, p=0.41)$, and transparency $(B=0.08, t=$ $1.46, \mathrm{p}=0.145)$ are not significantly related with influencer marketing. This suggests that target customers prefer influencers advertising products, services, and among others who are with strong reputation and credibility.

\subsection{Table 2}

\section{Mean Level of Agreement of Target Customers on Key Opinion Leaders' (KOL) Metrics and Average Effect of Influencer Marketing}

\begin{tabular}{c|c|c}
\hline & Mean & $\begin{array}{c}\text { Std. } \\
\text { Deviation }\end{array}$ \\
\hline Influencer Marketing & 3.22 & .48 \\
\hline $\begin{array}{c}\text { Advertising } \\
\text { Disclosure }\end{array}$ & 3.70 & .36 \\
\hline Transparency & 3.61 & .45 \\
\hline $\begin{array}{c}\text { Reputation and } \\
\text { Credibility }\end{array}$ & 3.69 & .40 \\
\hline
\end{tabular}

Table 2 presents the average level of agreement of the respondents on the Key Opinion Leaders' (KOL) metrics along with the mean of influencer marketing. It can be gleaned that among the 3influencer metrics, advertising disclosure yielded the highest mean of 3.70 along with a standard deviation of 0.36 . On the other hand, transparency yielded the lowest mean of 3.61 along with a standard deviation of 0.45 . Also, reputation and credibility yielded a mean of 3.69 along with a standard deviation of 0.40 . The results and findings presented in the table confirms that the respondents indicated their strong agreement on the influencer metrics tested.

\subsection{Table 3}

\section{Model Summary Table}

\begin{tabular}{c|c|c|c|c}
\hline Model & R & R Square & $\begin{array}{c}\text { Adjuste } \\
\mathrm{d} \mathrm{R} \\
\text { Square }\end{array}$ & $\begin{array}{c}\text { Std. Error of } \\
\text { the Estimate }\end{array}$ \\
\hline 1 & $.39^{\mathrm{a}}$ & .15 & .14 & .45 \\
\hline a. Predictors: (Constant), Reputation and
\end{tabular}

Credibility, Disclosure, Transparency

Table 3 presents the model summary of the data collected. As can be gleaned from the table, $r$ square and adjusted $\mathrm{R}$ square along with the standard error of the estimate are included. From the data, a $0.39 \mathrm{R}$ was computed which means that the predictors (Reputation and Credibility, Disclosure, Transparency) have an overall moderate positive relationship with influencer marketing. Moreover, the results yielded to a computed $\mathrm{R}$ square value of 0.15 which means that 15 percent of effective influencer marketing can be attributed to the three predictors. 


\subsection{Table 4}

\section{Analysis of Variance Table}

\begin{tabular}{l|l|c|c|c|c|c}
\hline \multicolumn{2}{c|}{ Model } & Sum of Squares & df & Mean Square & F & Sig. \\
\hline \multirow{3}{*}{1} & Regression & 15.27 & 3 & 5.09 & 25.10 & $.000^{\text {b }}$ \\
\cline { 2 - 7 } & Residual & 84.98 & 419 & .203 & & \\
\cline { 2 - 7 } & Total & 100.26 & 422 & & & \\
\hline
\end{tabular}

a. Dependent Variable: Influencer Marketing

b. Predictors: (Constant), Reputation and Credibility, Disclosure, Transparency

Table 4 presents the results and findings of this research if there is a significant effect of the three predictors to the dependent variable which is influencer marketing. As can be gleaned from the table, a F-value of 25.103 along with an associated probability value of 0.000 was computed. Since the probability value is less than 0.05 , the null hypothesis is rejected. Hence, there is sufficient evidence to indicate that the three predictors positively affect influencer marketing.

\subsection{Companies on Their Chosen Key Opinion Leaders Among Different Candidates}

The study investigated how companies choose their key opinion leaders among different candidates. This research inquired about the degree of the importance of certain characteristics that a key opinion leader must possess on the perspectives of the brand or company.

The first Key Opinion Leader metric evaluated is the social media audience that an influencer has. In this KOL, the respondents were asked to evaluate the social media audience of an influencer according to the number of followers, number of views, the engagement and interaction of the influencer to the viewers, and the consistency of reviews and updates of the influencer. The data shows that the respondents all strongly agreed with all the statements regarding social media influence. The data shows that the results yielded the highest mean of 3.81 along with a descriptive standard deviation of 0.45 thereby indicating their strong agreement that a company would likely use influencer who has a good engagement with his/her viewers. On the other hand, the results yielded the lowest mean of 3.66 with a standard deviation of 0.58 thereby indicating their strong agreement that a company would likely use influencer who has constant interaction with his/her followers.

Moreover, the second Key Opinion Leader metric evaluated is the influencer's consistency. In this KOL, the respondents were asked to evaluate the consistency of an influencer on the goal, mission, and objectives of a company, and that these do not contradict with their own. The results yielded the highest mean of 3.67 along with a standard deviation of 0.56 thereby indicating that their strong agreement that the influencer's mission, goals and objectives are consistent with the brands. On the other hand, the lowest mean of 3.52 along with a standard deviation of 0.66 was computed thereby indicating their strong agreement that an influencer's mission, goals and objectives do not contradict with the company's.

Additionally, the third Key Opinion Leader metric evaluated is the influencer's marketing skill. In this KOL, the respondents were asked to evaluate the marketing skill of an influencer along contents, technical skills, choice of theme, ability to persuade, and ability to critique. The results 
yielded the highest mean of 3.81 with a standard deviation of 0.47 thereby signifying their strong agreement that an influencer's content must be of good quality. However, the results yielded the lowest mean of 3.59 with a standard deviation of 0.57 thereby signifying their strong agreement that an influencer's technical skills should be decent.

Lastly, the fourth Key Opinion Leader metric evaluated is the influencer's reputation and credibility. In this KOL, the respondents were asked to evaluate the reputation and credibility of an influencer along their honesty, standing in the community, professional advice, and behaviour and attitude. The results yielded the highest mean of 3.79 along with a standard deviation of 0.50 thereby signifying their strong agreement on an influencer must be known for his/her honest reviews. On the other hand, the results showed the lowest mean of 3.59 along with a standard deviation of 0.62 thereby signifying their strong agreement that an influencer must be known for his/her professional advice.

\subsection{Target customer's Economic Behavior Towards Products/Brands or Companies as well as the Key Opinion Leaders}

This study examined the target customer's economic behavior towards products/brands or companies as well as the key opinion leaders. This research also examined the likelihood of buying, accepting and recommending products, referring reviews and products and using the products.

The first Key Opinion Leader (KOL) metric evaluated by the target customers is the influencer's social media audience. In this KOL, the respondents were asked regarding buying, using and endorsing products of influencers with a given number of followers. The results yielded the highest mean of 3.30 along with a standard deviation of 0.83 thereby indicating their strong agreement on buying, using and endorsing products of influencers who has followers over 1,000,000 followers. On the other hand, the results yielded the lowest mean of 2.75 along with a standard deviation of 0.81 thereby indicating their agreement to likely buying, using and endorsing products of influencers who has followers between 1,000 to 10,000 followers. From here, it can be deduced that customers tend to buy, use, and endorse products of influencers with higher number of followers.

The second Key Opinion Leader (KOL) metric evaluated by the target customers is the influencer's reputation and credibility. In this KOL, the respondents were asked regarding buying products, accepting reviews, recommending products, referring reviews of product, and using products reviewed and endorsed by influencers. The results yielded to the highest mean of 3.72 along with a standard deviation of 0.51 thereby resulting to their strong agreement that they buy products endorsed by influencers who are reputable and credible. On the other hand, the results yielded to the lowest mean of 3.54 along with a standard deviation of 0.62 thereby resulting to their strong agreement that they would likely recommend products endorsed by influencers who are reputable and credible.

The third Key Opinion Leader (KOL) metric evaluated by the target customers is the influencer's physical attributes. In this KOL, the respondents were asked regarding the how presentable an influencer is particularly on the looks or outside appearance. From the obtained data, the results yielded to the highest mean of 3.25 along with a standard deviation of 0.81 thereby indicating their strong agreement that they would likely buy products which are endorsed clearly by 
influencers. On the other hand, the results yielded the lowest mean of 3.03 along with a standard deviation of 0.82 thereby confirming their agreement that they would likely recommend products endorsed by influencers who are presentable and good looking.

Lastly, the fourth Key Opinion Leader (KOL) metric evaluated by the target customers is the influencer's transparency/advertising disclosure. In this KOL, the respondents were asked regarding accepting reviews, recommending products, referring reviews of product, and using products reviewed and endorsed by an influencer. From the obtained data, the results yielded to the highest mean of 3.12 along with a standard deviation of 0.83 thereby expressing their agreement that they would likely accept reviews made by influencers who clearly disclose the review as paid advertisement. However, the results yielded the lowest mean of 3.03 along with a standard deviation of 0.83 thereby expressing their agreement that they would likely recommend products endorsed by influencers who clearly discloses that it it's a paid advertisement.

\subsection{Target Customers' Buying, Accepting and Recommending Products, Referring Reviews and Products and Using the Products}

This research inquired on the preference of customers when they buy, accept and recommend products as well as when they are referring reviews and products and when using products.

The results yielded the highest mean of 3.14 along with a standard deviation of 0.68 thereby signifying their agreement that they would likely accept reviews made by influencers. On the other hand, the results yielded the lowest mean of 2.80 along with a standard deviation of 0.83 thereby signifying their agreement that they would likely recommend products endorsed by celebrities.

All the statements yielded a descriptive value of "Agree" and none resulted to a strong agreement. Also, it can be deduced that the target customers preferred products that are being endorsed and recommended by influencers compared to those that are referred by celebrities. This shows that social media has a strong influence on the choice of products of target customers.

\subsection{Ranks of the Attributes of Influencers According to Their Importance}

The target customers in this study ranked the important attributes that an influencer must possess according to importance. In this study, there are four metrics that were assessed by the target customers who served as respondents of the study which include the influencer's social media audience, reputation and credibility, physical attributes, and transparency/advertising disclosure.

Four hundred twenty-three (423) respondents indicated that an influencer's reputation and credibility should come first. This is supported by overall two hundred seventy-three (273) first ranks. Moreover, the influencer's transparency/advertising disclosure comes second as supported by two-hundred seventeen (217) first ranks. The influencer's social media audience placed third among the first ranks with one hundred forty respondents (140) indicating their choice while the influencer's physical attributes comes last with only fifty-one (51) first ranks.

\subsection{Effectiveness of Influencer-Focused Marketing}

This study also investigated the effectiveness of the key opinion leaders on the campaign. To measure the effectiveness of influencer-focused marketing, three questions were asked from the four hundred twenty-three (423) respondents on what social media platform do they often use and what 
platform do they utilize to view social media influencers review and recommendations of products and services. Also, they were asked if they buy and use these products that are recommended by KOLs.

From the data collected, the most often used social media platform by the respondents is Facebook with three hundred seventy-two (372) or 87.94 percent confirming it; Instagram comes second with three hundrer forty-four (344) or 81.32 percent; Youtube with three hundred fourteen (314) or 74.23 percent of the total respondents; Tiktok with two hundred thirty-three (233) or 55.08 percent; Twitter with thirty-six (36) or 8.51 percent; and other social media platforms with three (3) or 0.70 percent of the total respondents.

The respondents in this study which are considered as target customers also indicated the social media platform that they often use to view social media influencers review and recommendations of products and services. As presented from the table, Facebook was often use with three hundred six (306) or 72.34 percent; Instagram with two hundred seventy-eight (278) or 65.72 percent; Youtube with two hundred two (202) or 47.75 percent of the total respondents; Tiktok with one hundrer ninety-eight (46.80) or 46.80 percent; Twitter with twenty-four (36) or 5.67 percent; and other social media platforms with three (3) or 0.70 percent of the total respondents.

Lastly, the respondents were asked if they buy and use these products that are recommended by KOLs from the social media platform that they have chosen. It was found out that two hundred fifty-eight (258) or 60.99 percent signified that they buy and utilize products that are recommended by KOLs from social media platform while the other one hundred sixty-five (165) or 39.00 percent signified otherwise.

\subsection{Brands and Companies Known for Their KOLs}

The target customers were asked about what products/brands or services that have KOLs they are familiar with. Also, they were asked about who, among the different social media influencers, they consider as credible and why.

Based on the gathered and collected responses, the products/brands or services that they are familiar with include Unilever, cosmetic brands such as Watson's, online shopping centers like Lazada and Shopee, food brands like Jollibee and McDonald's, and among others.

Also, among the different social media influencers they consider as credible include CongTV, Doc Adam, Toni Sia, Alex Gonzaga, and among others. It is important to note, however, that the target customers also included some names of local and international celebrities. When asked about why they have chosen these KOLs, they have indicated that this is because of their credibility as influencers or endorsers of the product and that these influencers are being seen to be using the products that they are endorsing.

\section{Conclusion}

Based on the results, findings, and summary of this study, the following conclusions were generated: (1) among the four metrics included in this study, companies tend to choose an influencer/KOL with a good reputation and high credibility over the other influencer metrics. On the other hand, they least choose an influencer/KOL based on consistency; (2) target customers buy, use, 
and recommend products of Key Opinion Leaders (KOLs) or influencers who have good reputation and high credibility over the other influencer metrics. However, they least prefer an influencer/KOL based on transparency or advertising disclosure; (3) target customers buy, accept and recommend products endorsed by influencers over celebrities; (4) among the influencer/KOL metrics, the target customers prefer reputation and credibility over other metrics. On the other hand, they consider physical attributes last; (5) reputation and credibility as Key Opinion Leader (KOL) metric is the only influencer metric that has a significant relationship to influencer marketing. However, all the three influencer metrics (advertising disclosure, transparency, and reputation and credibility) have a positive effect on influencer marketing; and (6) collectively, all the three Key Opinion Leader (KOL)/influencer metrics account for a positive effect on influencer marketing.

In light of the outcomes and conclusions shown in this study, the following recommendations are forwarded: (1) companies endorsing brands of products, services, and among others should consider using Key Opinion Leader (KOL) metrics in the selection of their endorsers. Among the metrics that they should consider include the reputation and credibility, physical attributes, consistency, and among other metrics; (2) Key Opinion Leaders (KOLs) should considering maintaining a good reputation and credibility over other metrics especially that they are social figures being looked up to by target consumers; and (3) other Key Opinion Leader (KOL) metrics should be included and studied in the conduct of future researches to investigate its effect in influencer marketing.

\section{References}

[1] Argyris, Y. A., Muqaddam, A., \& Miller, S. (2020). The effects of the visual presentation of an influencer's extroversion on perceived credibility and purchase intentions-moderated by personality matching with the audience. Journal of Retailing and Consumer Services, 59. 10.1016/j.jretconser.2020.102347

[2] Bentley, K., Yalcin, T., Pehlivan, E., Nistor, C., \& Chu, C. (2021). Social media engagement for global influencers. Journal of Global Marketing, 34(3), 205-219. https://doi.org/10.1080/08911762.2021.1895403

[3] Casais, B., Camilleri, M. A., \& Rios, I. (2021). The effect of macrocelebrity and microinfluencer endorsements on consumer-brand engagement in Instagram. Strategic Corporate Communication in the Digital Age. 1st ed, Emerald Publishing. 10.1108/9781-80071-264-520211008.

[4] Dada, G. A. (2017, November 14). Council Post: What Is Influencer Marketing and How Can Marketers Use It Effectively? Forbes.http:

//www.forbes.com/sites/forbescommunicationscouncil/2017/11/14/what-is-influencermarketing-and-how-can-marketers-use-it-effectively (Accessed on Aug 23, 2018).

[5] Evans, N. J., Phua, J., Lim, J., \& Jun, H. (2017). Disclosing Instagram influencer advertising: The effects of disclosure language on advertising recognition, attitudes, and behavioral intent. Journal of Interactive Advertising, 17(2), 138-149. https://doi.org/10.1080/15252019.2017.1366885. 
[6] Freberg, K., Graham, K., McGaughey, K., \& Freberg, L. A. (2011). Who are the social media influencers? A study of public perceptions of personality. Public Relations Review, 37(1), 90-92. https://doi.org/10.1016/j.pubrev.2010.11.001.

[7] Han, H., Yi, J., Jun, S., \& Ahn, S. (2020). How do followers infer the motives behind an influencer's advertising disclosures? Asia Pacific Journal of Marketing and Logistics, 33 (5). https://doi.org/10.1108/apjml-06-2019-0397.

[8] IZEA. (2020, November 20). Influencer marketing vs. traditional marketing: Which is better? - GRIN - influencer marketing software. GRIN. https://grin.co/ blog/influencermarketing-vs-traditional-marketing-which-is-better/ (Accessed on Aug10, 2021).

[9] Lee, K. (2018). 2018: Year of the Influencer Marketing Implosion? Available at:https://marketingland.com/2018-year-influencer-year-influencer-marketing-implosion231617. (Accessed on Jul 10, 2021).

[10] Phua, J., Lin, J., \& Lim, D. (2018). Understanding consumer engagement with celebrityendorsed e-cigarette advertising on Instagram. Computers in Human Behavior, 84. 10.1016/j.chb.2018.02.031.

[11] Schouten, A. P., Janssen, L., \& Verspaget, M. (2021). Celebrity vs. influencer endorsements in advertising: the role of identification, credibility, and product-endorser fit. Leveraged Marketing Communications, 208-231. https://doi.org/10.4324/9781003155249-12.

[12] Shareef, M. A., Mukerji, B., Dwivedi, Y. K., Rana, N. P., \& Islam, R. (2019). Social media marketing: Comparative effect of advertisement sources. Journal of Retailing and Consumer Services, 46, 58-69. https://doi.org/10.1016/j.jretconser.2017.11.001.

[13] Stewart, R. (2017, September 22). UK ad regulator singles out Instagram for failing to label paid-for content. The Drum. https://www.thedrum.com/news/2017/09/21/uk-ad-regulatorsingles-out-instagram-failing-label-paid-content.

[14] Wang, S. W., \& Scheinbaum, A. C. (2017). Enhancing brand credibility via celebrity endorsement. Journal of Advertising Research, 58(1), 16-32. https://doi.org/10.2501/jar2017-042.

[15] Weismueller, J., Harrigan, P., Wang, S., \& Soutar, G. N. (2020). Influencer endorsements: How advertising disclosure and source credibility affect consumer purchase intention on social media. Australasian Marketing Journal, 28(4), 160-170.

https://doi.org/10.1016/j.ausmj.2020.03.002.

[16] Wojdynski, B. W., \& Evans, N. J. (2015). Going native: Effects of disclosure position and language on the recognition and evaluation of online native advertising. Journal of Advertising, 45(2), 157-168. https://doi.org/10.1080/00913367.2015.1115380.

[17] Woodroof, P. J., Howie, K. M., Syrdal, H. A., \& VanMeter, R. (2020). What's done in the dark will be brought to the light: Effects of influencer transparency on product efficacy and purchase intentions. Journal of Product \& Brand Management, 29(5), 675-688. https://doi.org/10.1108/jpbm-05-2019-2362. 